\title{
SIZE EFFECTS IN RUTHENIUM-BASED THICK-FILM RESISTORS: RUTILE VS. PYROCHLORE-BASED RESISTORS
}

\author{
M. PRUDENZIATI, F. SIROTTI, M. SACCHI, \\ B. MORTEN, A. TOMBESI \\ Department of Physics, University of Modena Via G. Campi 213/A, 41100 Modena, Italy \\ T. AKOMOLAFE \\ Phys. Dept., University of Ilorin, NIGERIA
}

(Received September 27, 1990)

\begin{abstract}
The size effect, namely the change of sheet resistance, $R_{s}$ as a function of resistor length, has been investigated in layers whose conductive phase evolves from $\mathrm{Pb}$-rich ( $\mathrm{Ru}$-deficient pyrochlores) to $\mathrm{Pb}_{2} \mathrm{Ru}_{2} \mathrm{O}_{6.5}$ and finally to $\mathrm{RuO}_{2}$ by increasing the firing temperature. It is found that $\mathrm{Bi}$ diffusion from the terminations is responsible for lower sheet resistance values in shorter resistors whatever the conductive phase is. On the contrary, $\mathrm{Ag}$ diffusion is responsible for lower sheet resistance values in shorter resistors only in the case of ruthenate conductive grains while the reverse is observed in $\mathrm{RuO}_{2}$-based layers. Size effect can be suppressed with $\mathrm{Pt} / \mathrm{Au}$-based terminations provided that no $\mathrm{Bi}$ is contained and with Au-metallorganic-based contact provided that the peak firing temperature is not too high.
\end{abstract}

Key words: thick film resistors, size effects, electronic components

\section{INTRODUCTION}

The size effect in thick-film resistors, namely the change of sheet resistance, $R_{s}$ as a function of the resistor length, 1 is of great concern for designers of hybrid circuits and their users, since it greatly affects the performance and reliability of these resistors, preventing, among other things, a precise design of the electrical properties of short resistors ${ }^{1}$.

Several investigations have been published on these effects in Ru-based resistors, either in the form of $\mathrm{RuO}_{2}$ or pyrochlore-type ruthenates.

At least two different causes of the size effect can be identified. The first one is associated with the change of shape (in particular thickness) of resistors when their length is varied. In this case the ratio between the actual resistance $R$ and the aspect ratio (length 1 /width $w$ ), does not represent the actual sheet resistance $R_{a}$, since the actual thickness is not constant for the whole set of resistors. Then $R_{s}$ changes according to different 1 , even if the resistivity of the material is constant into the resistive layer. This is usually a minor effect in Ru-based resistors, compared to the second source of size effects, namely a change of resistivity along the layer, associated with a compositional change.

The latter frequently occurs near the terminations due to interactions between the conductive layers and the resistive layers. 
Different types of interactions can occur. A compound formation involving Pdbearing terminations and pyrochlore-based resistors have been reported ${ }^{2}$. However, diffusive processes are probably the most important causes of size effect in $\mathrm{Ru}$ based resistors.

At least two species have been identified as responsible for diffusive processes, namely $\mathrm{Bi}^{3}$ and $\mathrm{Ag}^{4-8}$. Recently it has been shown ${ }^{8}$ that $\mathrm{Ag}$ diffusion into $\mathrm{RuO}_{2-}$ based resistors exhibit very peculiar behaviours; in fact the silver diffusion coefficient is largely dependent on the surface area of $\mathrm{RuO}_{2}$ particles (i.e. on $\mathrm{RuO}_{2}$ grain size and concentration) as well as on the glass-matrix composition, and $\mathrm{Al}$ counterdiffusion occurs in resistors with an $\mathrm{Al}_{2} \mathrm{O}_{3}$-bearing glassy matrix due to either the glass formulation or diffusion from the alumina substrate. The $\mathrm{Ag}-\mathrm{Al}$ interdiffusion is responsible for an "inverse" size effect, i.e. shorter resistors exhibit larger sheet resistance than longer resistors.

In this paper we will show that this peculiar phenomena are restricted to $\mathrm{RuO}_{2}$ based systems (without any additive included, i.e. made of solely lead-silicate or boron-lead silicate glass frit and $\mathrm{RuO}_{2}$ powders). Different behaviours are found in ruthenate-based resistors, since in this latter case a "direct" effect (i.e. lower sheet resistance in shorter samples) is observed, no matter the glass composition and interaction with the substrate, even if Ag largely diffuses into the resistive layers.

These results can allow us to elucidate the electrical transport in thick-film resistors.

\section{EXPERIMENTAL}

\section{A. Samples and Method}

This investigation was performed on resistive layers whose conductive phase evolves from $\mathrm{Pb}$-rich (Ru-deficient) pyrochlores to $\mathrm{Pb}_{2} \mathrm{Ru}_{2} \mathrm{O}_{6.5}$ and finally to $\mathrm{RuO}_{2}$ by increasing the firing temperature. Preparation of the paste starts from powders obtained by precipitation of $\mathrm{RuCl}_{3}$ on a $\mathrm{Pb}$-containing glass of the percentage weight composition $\mathrm{SiO}_{2}: \mathrm{PbO}: \mathrm{B}_{2} \mathrm{O}_{3}=22: 59: 19$. The added $\mathrm{RuCl}_{3}$ was equivalent to an amount of $3.8 \mathrm{wt} \% \mathrm{Ru}\left(5 \mathrm{wt} \% \mathrm{RuO}_{2}\right)$. Details of the preparation of the ink have been given previously ${ }^{9}$ together with results concerning the evolution of the structural and electrical properties of the layers after heat treatment at various temperatures. For the present study, several inks were selected for the resistor terminations. Two Ag-bearing conductors were prepared with $\mathrm{Pd}$ and $\mathrm{Ag}$ powders in the relative ratio of $1: 3$ respectively. The composition of the glass bonding agent was the same as the glass frit used for the resistors. However, in one case (2120), a small quantity of $(10 \mathrm{wt} \%) \mathrm{Bi}_{2} \mathrm{O}_{3}$ was added to the glass as a flux. The Ag-free conductors were selected between the commercially available materials. 8081-A is a metallorganic Au-based ink. 9596 is a Pt/Au-based conductor with a glass bonding agent containing $\mathrm{Bi}$. 5805 is a "fritless" $\mathrm{Pt} / \mathrm{Au}$-based ink which according to microprobe analyses, resulted free from $\mathrm{Bi}$ but with $\mathrm{Mn}$ and a small amount of $\mathrm{Pb}$ rich silicate. Table 1 summarises the composition of the conducting materials either as known from preparation or derived from qualitative EDS analyses on dried inks (organic parts neglected). 
TABLE 1

Composition of conductive layers used as terminations

\begin{tabular}{llll}
\hline Ink & Main Elements & Flux & Other constit. \\
2120 & $\mathrm{Pd}: \mathrm{Ag}=1: 3$ & $\mathrm{Bi}$ & Borosilicate glass \\
2130 & $\mathrm{Pd}: \mathrm{Ag}=1: 3$ & None & Borosilicate glass \\
5805 & $\mathrm{Pd}: \mathrm{Au}$ & None & Leadsilicate glass \\
$8081-\mathrm{A}$ & $\mathrm{Au}$ & $\mathrm{None}$ & None \\
9596 & $\mathrm{Pt} / \mathrm{Au}$ & $\mathrm{Bi}$ & Leadsilicate glass \\
\hline
\end{tabular}

Resistors were screen printed on $\mathrm{Al}_{2} \mathrm{O}_{3}$ substrates (Hoechst Ceram. Tec 708) with prefired terminations (prepared at $\mathrm{T}_{\mathrm{f}}=950^{\circ} \mathrm{C}$ ) and fired at different firing temperatures in the range $600-900{ }^{\circ} \mathrm{C}$. The resistor patterns contain samples of fixed width $(2 \mathrm{~mm})$ and different lengths (from $0.5-10 \mathrm{~mm}$ ) for the study of size effects.

Resistivity measurements were performed at $300 \mathrm{~K}$ using a Philips autoranging multimeter (PM 2528).

\section{B. Analyses}

Observations in scanning electron microscope (SEM) and analyses in energy dispersive spectroscopy (EDS) were performed with Philips PX 500 system equipped with a $\mathrm{Si}(\mathrm{Li})$ detector with $\mathrm{Be}$ window, enabling the detection of elements with $\mathrm{Z}$ $>10$.

$\mathrm{X}$-ray diffraction (XRD) measurements were performed using $\mathrm{Cu} \mathrm{K}$ emission line (Ni filter) by means of a Philips PW 1700 diffractometer. XRD patterns were collected on samples etched in $\mathrm{HF}: \mathrm{HNO}_{3}: \mathrm{H}_{2} \mathrm{O}=3: 1: 50$ volume for $1 \mathrm{~min}$ in order to remove the glassy matrix and enhance the peaks of the crystalline phases. Areas under these peaks were measured in samples fired at various firing temperatures and, for reference, in powders of $\mathrm{RuO}_{2}$ and $\mathrm{Pb}_{2} \mathrm{Ru}_{2} \mathrm{O}_{6.5}$.

\section{RESULTS}

Samples prepared at lower temperatures $\left(600-800{ }^{\circ} \mathrm{C}\right)$ exhibited the reflections corresponding to a cubic structure identified as a pyrochlore phase. However, the peak positions shift continuously in accordance with reduction of the lattice parameter from $a_{o}=10.6 \AA$ in samples fired at $600{ }^{\circ} \mathrm{C}$ to $\mathrm{a}_{o}=10.26 \AA$ in samples prepared at $850{ }^{\circ} \mathrm{C}$. Moreover, as the firing temperature increases from 700 to $950{ }^{\circ} \mathrm{C}$ two further effects are observed:

a) The pyrochlore height peaks (e.g. (222) peak near $2 \theta=30 \mathrm{deg}$.) decrease by increasing the firing temperature; and

b) Weak and broad reflections of the $\mathrm{RuO}_{2}$ rutile phase, (near $28.2 \mathrm{deg}$.) are observed first $\left(\mathrm{T}_{\mathrm{f}}=700{ }^{\circ} \mathrm{C}\right)$ which completely substitutes for pyrochlore phase at $950{ }^{\circ} \mathrm{C}$.

Fig. 1a shows these results by comparing a segment of the XRD patterns of samples fired at different temperatures. An approximate evaluation of the relative fraction of pyrochlore converted in rutile phase was obtained through the ratio of area of the XRD patterns of the two phases taking into account the intensity of 

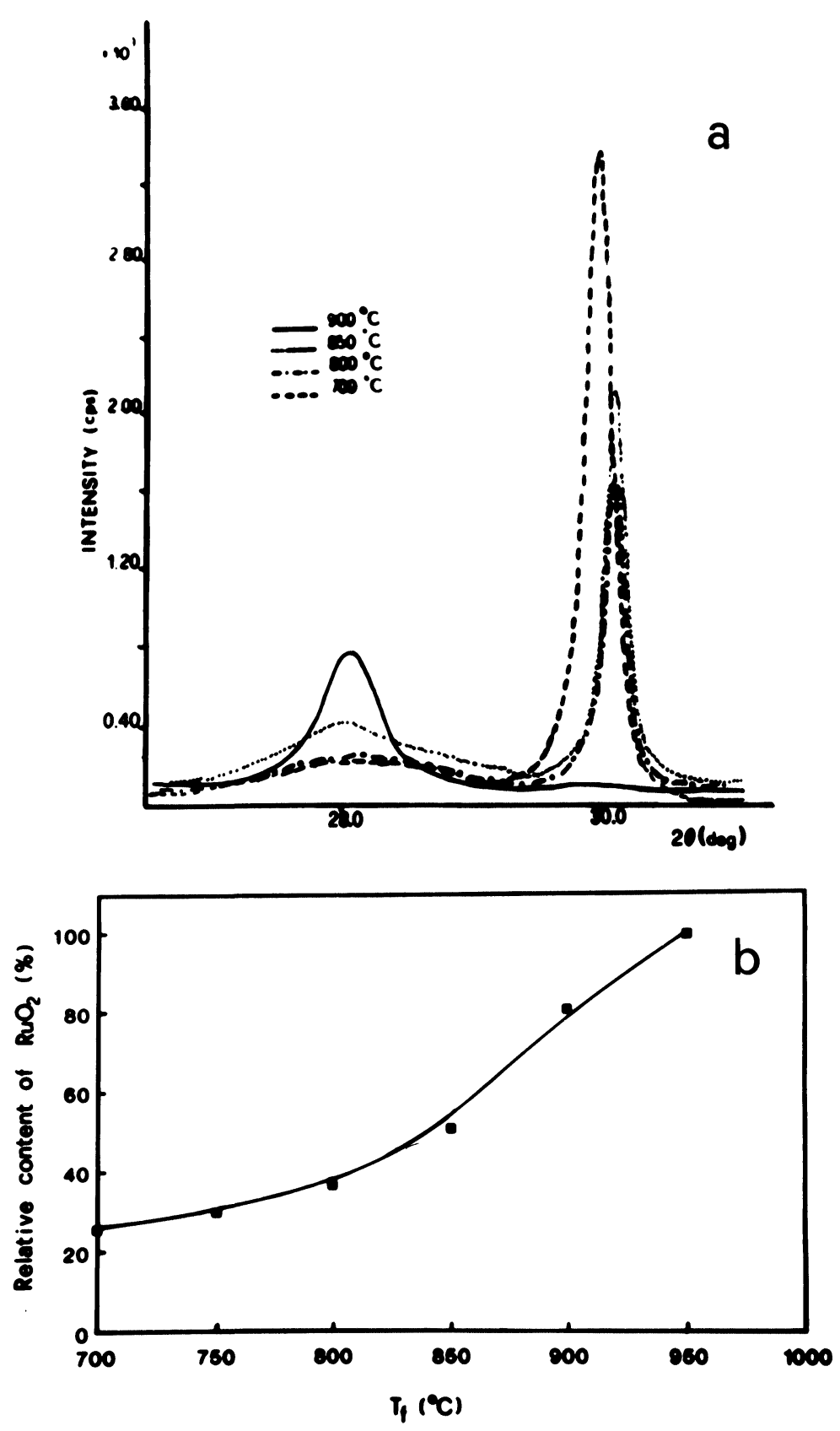

FIGURE 1 (a) The salient part of XRD patterns of Resistive layers fired at various peak temperatures. The correspondence between crystallographic planes and $2 \theta$ values is as follows: $\mathrm{RuO}_{2}(110) \rightarrow 28.135^{\circ}$; $\mathrm{Pb}_{2} \mathrm{Ru}_{2} \mathrm{O}_{6.5}$ (222) $\rightarrow 30.15^{\circ}$. (b): Approximate relative content of $\mathrm{RuO}_{2}$ evaluated from the normalized area of rutile/(rutile + pyrochlore) XRD reflections. 
reflection of the reference powders. This approximate evaluation is reported in Fig. $1 \mathrm{~b}$. It is apparent that in samples prepared at $850{ }^{\circ} \mathrm{C}$ the conductive phase is made of about $50 \% \mathrm{RuO}_{2}$ and $50 \%$ pyrochlore grains.

Fig. 2 shows the size effect, namely the effect of resistor length, 1 on the effective sheet resistance, $R_{s}$ of the samples fired at $T_{f}=850{ }^{\circ} \mathrm{C}$ and terminated with four different types of conductors. The direct effect, namely a lower effective sheet resistance for short resistors, is exhibited in the case of Ag-free terminations. The presence of $\mathrm{Ag}$ in the conductors is responsible for a great inverse effect, namely larger effective sheet resistance in the short resistors. It can be seen that $\mathrm{Bi}$ can only attenuate the consequence of $\mathrm{Ag}$ diffusion. The small variation of effective sheet resistance observed in resistors with "fritless" conductors is due to a geometrical effect. An increase of the peak firing temperature strongly enhances this behaviour (see Fig. 3 where the size effect of the resistors prepared at $900{ }^{\circ} \mathrm{C}$ is reported), particularly in the case of Bi-free Ag-bearing conductors.

The effect of the peak firing temperature as a consequence of $\mathrm{Ag}$ diffusion into the resistors is shown in Fig. 4. Here, it is interesting to note that at lower tem-

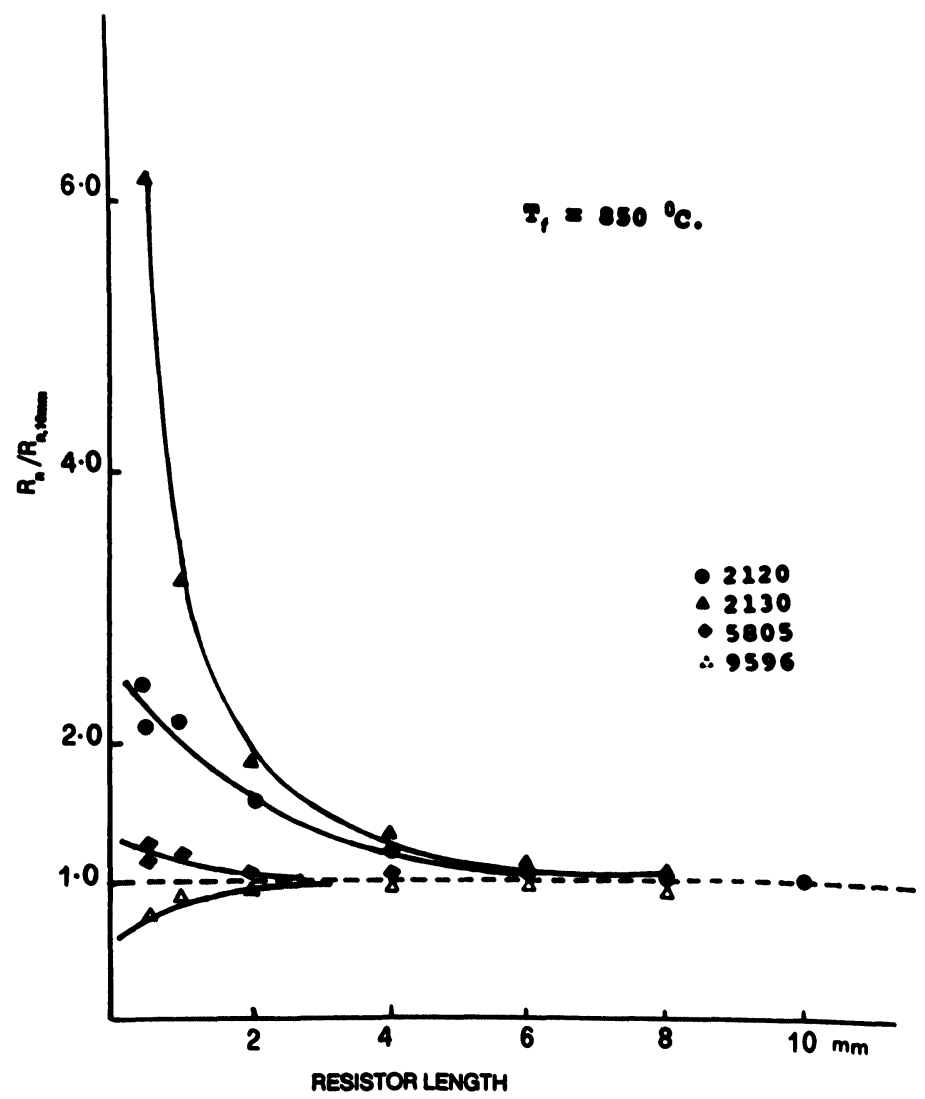

FIGURE 2 Normalised Sheet Resistance vs. Resistor length for the resistor with four different terminations (Note: $\mathrm{T}_{\mathrm{f}}=850^{\circ} \mathrm{C}$ ). 


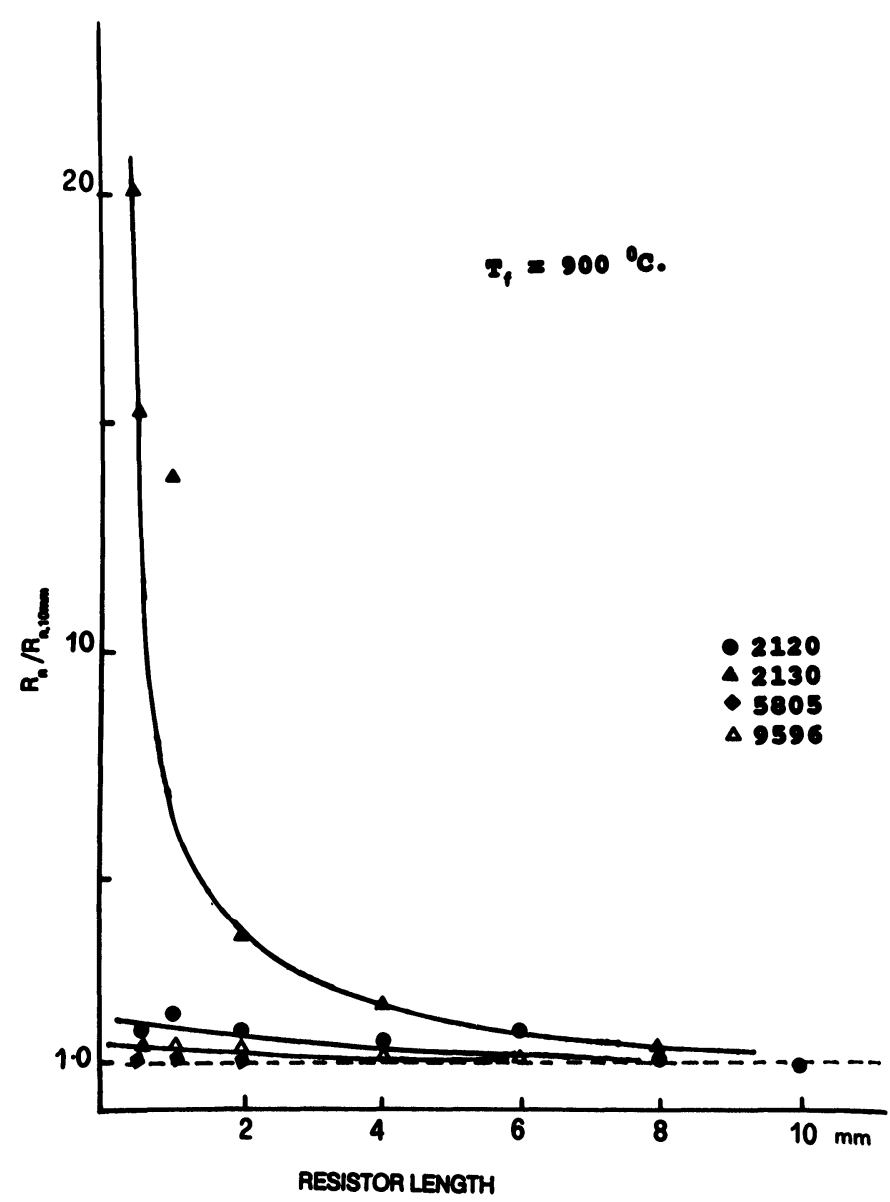

FIGURE 3 Normalised Sheet Resistance vs. Resistor length for the resistor with four different terminations (Note: $\mathrm{T}_{\mathrm{f}}=900^{\circ} \mathrm{C}$ ).

peratures $\left(\mathrm{T}_{\mathrm{f}}<750{ }^{\circ} \mathrm{C}\right)$ a direct effect is observed, while at higher temperatures $\left(\mathrm{T}_{\mathrm{f}}>800^{\circ} \mathrm{C}\right)$ the inverse effect is observed. This peculiar consequence of $\mathrm{Ag}$ diffusion should be related to a change of microstructure of the resistive layer, as explained later.

The consequence of $\mathrm{Bi}$ diffusion is quite different from that of $\mathrm{Ag}$ diffusion as shown in Fig. 5. Here as temperature increases the direct effect becomes more pronounced.

In order to remove almost completely the size effect both $\mathrm{Bi}$ and $\mathrm{Ag}$ have to be absent in the conductive layers as in the case of 5850 (Pt/Au terminations). In fact in this case, the sheet resistance does not change more than $\pm 15 \%$ which is the usual scattering of sheet resistance values due to variation of the thickness and aspect ratio as well as inhomogeneity of thick film resistors. 


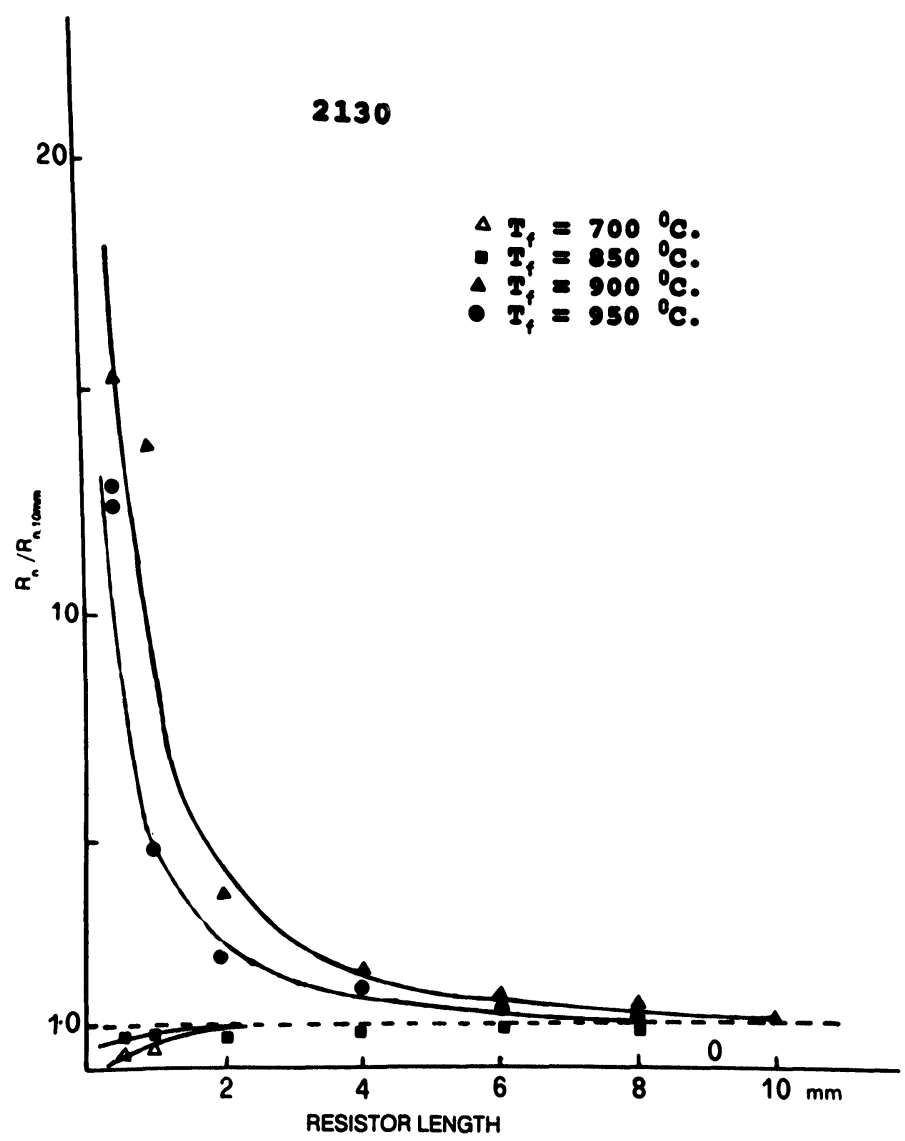

FIGURE 4 Variation of Normalised Sheet Resistance with Resistor length for the resistor terminated with 2130 and fired at different peak temperatures.

Our attempts to avoid the size effect with the use of metallorganic Au-based terminations were unsuccessful for $\mathrm{T}>800^{\circ} \mathrm{C}$. In fact, this conductor has a poor compatibility with the resistive material as well as with the alumina substrate at high temperature in agreement with the recommendation of the manufacturer who suggests a peak firing temperature in the range $625-850{ }^{\circ} \mathrm{C}$ with an optimum at $825^{\circ} \mathrm{C}$. Fig. 6 illustrates this property. It can be seen that the region where the resistor and the conductor overlap is affected by intermixing of the two types of layers. Consequently, a good low resistive contact can not be formed (see Figs. 6a $\& \mathrm{~b})$. The metallic layer suffers from lack of contact also far from the resistor. The presence of voids are observed in samples prepared at $T_{f}=850{ }^{\circ} \mathrm{C}$ (see Fig. 6c) while the formation of disconnected islands results from heating at higher temperatures (Fig. 6d). This finding suggests strong driving forces for nucleation and weak interface between gold and alumina. As a consequence, resistance of the metal lines increases with the firing temperature. 


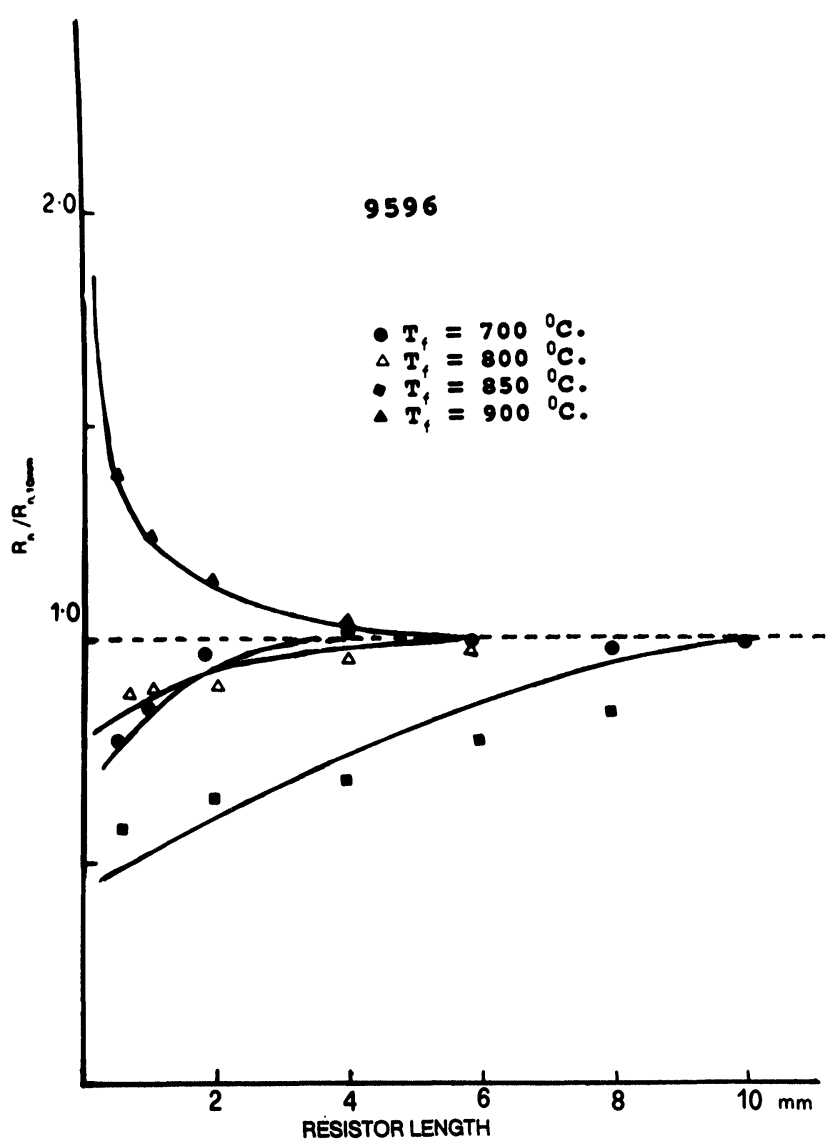

FIGURE 5 Variation of Normalised Sheet Resistance with Resistor length for the resistor terminated with 9596 and fired at different peak temperatures.

\section{DISCUSSION}

The described experiments have shown how complex the size effect can be. In fact, the same resistive layer on the same substrate exhibits a behaviour depending on the composition of the terminations but also an inversion of the effect itself by changing the firing temperature. This latter is due to silver diffusion. If we reasonably assume that the diffusion of elements from the termination does not affect the conductive phase transformation in the resistors, we can include all the observed effects in a single picture, according to the following statements:

i) $\mathrm{Bi}$ diffusion is responsible for a decrease of resistance in $\mathrm{RuO}_{2}$ as well as in ruthenate-based resistors ${ }^{3}$.

ii) $\mathrm{Ag}$ diffusion is responsible for a decrease of resistance in ruthenate-based resistors ${ }^{5}$ as well as in $\mathrm{RuO}_{2}$-based systems, provided that the latter are free from aluminium $^{8}$; and 


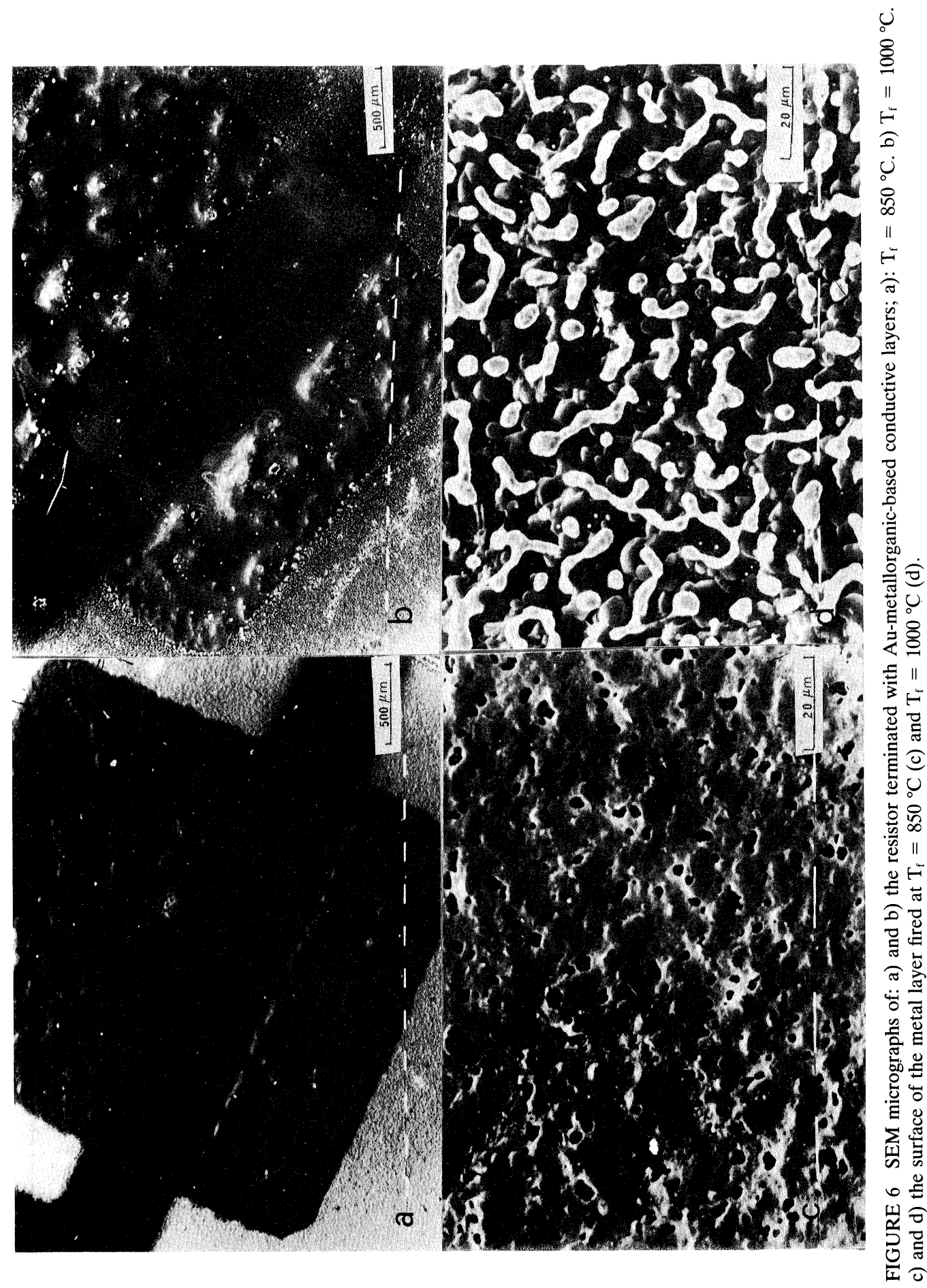


iii) The resistance of $\mathrm{RuO}_{2}$-based resistors containing aluminium, either due to its presence in the glass frit or interdiffusion from the substrate increases as a consequence of silver diffusion.

In this frame work, a qualitative explanation of the results concerning the size effect in these resistors can be easily given. With reference to Fig. 2, the direct effect observed with 9596 terminations is closely related to the previous point (i) regardless of the composition of the conductive phase inside the resistor. On the contrary, the effect given by $\mathrm{Ag}$-bearing conductors requires that $\mathrm{RuO}_{2}$ grains are present in a considerable quantity (in accordance with the result shown in Fig. 1b), as well as the presence of aluminium diffused from the substrate. Evidence of considerable interactions between the glass and alumina have been reported ${ }^{10}$.

An increase of the firing temperature means an increase of diffusivity for $\mathrm{Bi}$, $\mathrm{Ag}$ and $\mathrm{Al}$ as well as a further transformation of the conductive phase into $\mathrm{RuO}_{2}$. Consequently, according to point (ii), the direct effect due to $\mathrm{Bi}$ diffusion is enhanced with 9596 terminations and similarly the reverse effect due to $\mathrm{Ag}$ diffusion is more evident according to point (ii) as in fact observed in Fig. 3. The results of Fig. 4, where terminations based on $\mathrm{Ag}$ without $\mathrm{Bi}$ are considered, can be realised according to the correlation between the $\mathrm{Ag}$ diffusion and its consequence and according to the nature of the conductive phase in the resistor. In fact, at lower temperatures $\left(700-750{ }^{\circ} \mathrm{C}\right)$ interactions between glass and alumina have already taken place concurrently with Ag diffusion in the resistors; the direct effect is observed in agreement with the presence of the conductive grains mainly consisting in a ruthenate phase. As far as temperature increases and ruthenate is transformed into $\mathrm{RuO}_{2}$ inverse effect becomes evident. Here the absence of $\mathrm{Bi}$ in the terminations as well as the identity of composition of the glass in the conductive and resistive layers warrant that an inversion of the size effect is exclusively related to the phase transformation of the conductive grains in the resistor.

Finally, the results of Fig. 5 support the contention that $\mathrm{Bi}$ is responsible for the direct effect whatever the conductive phase in the resistors.

It is interesting to note that the diffusion of $\mathrm{Bi}$ partially suppresses the effect of Ag diffusion. Other elements (e.g. Mn) are even more effective in suppressing the inverse effect. These are the same elements usually introduced in $\mathrm{RuO}^{2}$-based resistors for the control of the Temperature Coefficient of Resistance (TCR) ${ }^{11-12}$. This is the reason why the inverse size effect is rarely observed in the commercial pastes.

\section{CONCLUSIONS}

The electrical properties of ruthenate- and ruthenium dioxide-based resistors exhibit some similarities but also some important differences ${ }^{13-14}$. The size effect due to silver diffusion from terminations seems to be one of the most striking distinctive features. Reverse size effects were already observed occasionally ${ }^{6}$ e.g. in silver terminated commercial resistors and systematically found in our $\mathrm{RuO}_{2}$-based model systems $^{8}$ while the direct size effect was always found in ruthenate-based resistors ${ }^{5}$.

However, this investigation is the closest we have come to show that the con- 
sequence of silver diffusion (and related $\mathrm{Al}$ interdiffusion ${ }^{8}$ ) on electrical properties is dependent on the nature of the conductive phase. In fact, we have found an inversion of the size effect in a single system, by changing "only" (or mainly) the conductive phase from $\mathrm{Pb}$-pyrochlore in $\mathrm{RuO}_{2}$ while the glass matrix remains essentially the same (except for the minor changes due to the exchange reactions giving rise to the phase transformation itself).

Further investigations are required to understand in which way silver is located into the microstructure of the Ru-based resistors (bond state with glass and/or the conductive grains) in model resistors which give simpler systems and hopefully offer a possibility to clarify the behaviour of these very complex resistors.

\section{ACKNOWLEDGEMENTS}

We are grateful to Drs. E. Argentino, G. Ruffi (Chimet SpA, Arezzo, Italy) for preparation of inks and to the staff of CIGS (Centro Interdipartimentale Grandi Strumenti) of the University of Modena for assistance with SEM-EDS equipments. The work was partially supported by MURST (Ministero della Universitá e Ricerca Scientifica e Technologica). One of us (T.A.) is grateful to the University of Ilorin, Nigeria for granting him a study leave and did this work with the support of a grant from the ICTP Programme for Training and Research in Italian Laboratories, Trieste, Italy.

\section{REFERENCES}

1. R.D. Jones, "Hybrid Circuit Design and Manufacture", Marcel Dekker Inc. (1982) N.Y. $1^{\text {st }}$ Edn.

2. M. Hrovat, F. Jan and D. Kolar, "The Interaction Between Thick Film Conductors and Low Ohmic Resistors", Hybrid Circuits No 10 (1986) 14-15.

3. M. Prudenziati, B. Morten, L. Moro, L. Olumekor and A. Tombesi, "Interactions Between Thick Film Resistor and Terminations: The Role of Bi”, J. Phys. D: Applied Phys. 19 (1986) 275-282.

4. S.B. Garvin and S.J. Stein: "The Influence of Geometry and Conductor Terminations in Thick Film Resistors." Proc. Elect. Comp. Conf. Washington D.C. (1970) 190.

5. A. Cattaneo, M. Cocito, F. Forlani and M. Prudenziati: "Influence of the Metal Migration from Screen- and Fired Terminations on the Electrical Characteristics of Thick Film Resistor." Electr. Comp. Sci. and Tech. vol. 4 (1977) 205-211.

6. B. Morten, M. Prudenziati and A. Taroni: "Metal Migrations in Thick Film Resistors: The Effect of The Substrate." Inter. J. Hybrid Microlect. 4 (1981) 341-346.

7. A. Bellardo and G. Lovati, "Performances of Thick Film Resistor with Reduced Dimensions", Hybrid Circuits No. 4 (1984) 26-31.

8. M. Prudenziati, B. Morten, G. Ruffi, E. Argentino and C. Iachetti: "Size Effect Due to Silver Diffusion in $\mathrm{RuO}_{2}$-Based Resistor." Proc of the $7^{\text {th }}$ European Hybrid Microel. Hamburg, FRG. May (1989) Paper n8.4.

9. B. Morten, M. Prudenziati, M. Sacchi and F. Sirotti: "Phase Transitions in Ru-Based Thick Film (Cermet) Resistor.” J. Appl. Phys. 63 (1988) 2267-2271.

10. M. Prudenziati, B. Morten, F. Cilloni, G. Ruffi and M. Sacchi. "Interactions Between Alumina and High Lead Glasses For Hybrid Components.” J. Appl. Phys. 65 (1989) 146.

11. T. Inokuma, Y. Taketa and M. Haradome: "Strange Temperature Characteristics of $\mathrm{RuO}_{2}$-Based Thick Film Resistors.” Elect. Comp. Sci. and Tech. Vol. 9 (1982) 205-207.

12. Shen-Li Fu, Jing-Ming Liang, Toyotaro Shiramatsu and Tien-Shou Wu: "Effects of Glass Modifiers on the Electrical Properties of Thallium Oxide Thick Film Resistors." Mat. Res. Bull. Vol. 12 (1977) 569-576.

13. P.F. Carcia, A. Ferretti and A. Suna: "Particle Size Effects in Thick Film Resistors." J. Appl. Phys 53 (1982) 5282-5288.

14. P.F. Carcia, A. Suna and W.D. Childers: "Electrical Conduction and Strain Sensitivity in $\mathrm{RuO}_{2}$ Thick Film Resistors.” J. Appl. Phys. 54 (1983) 6002-6008. 

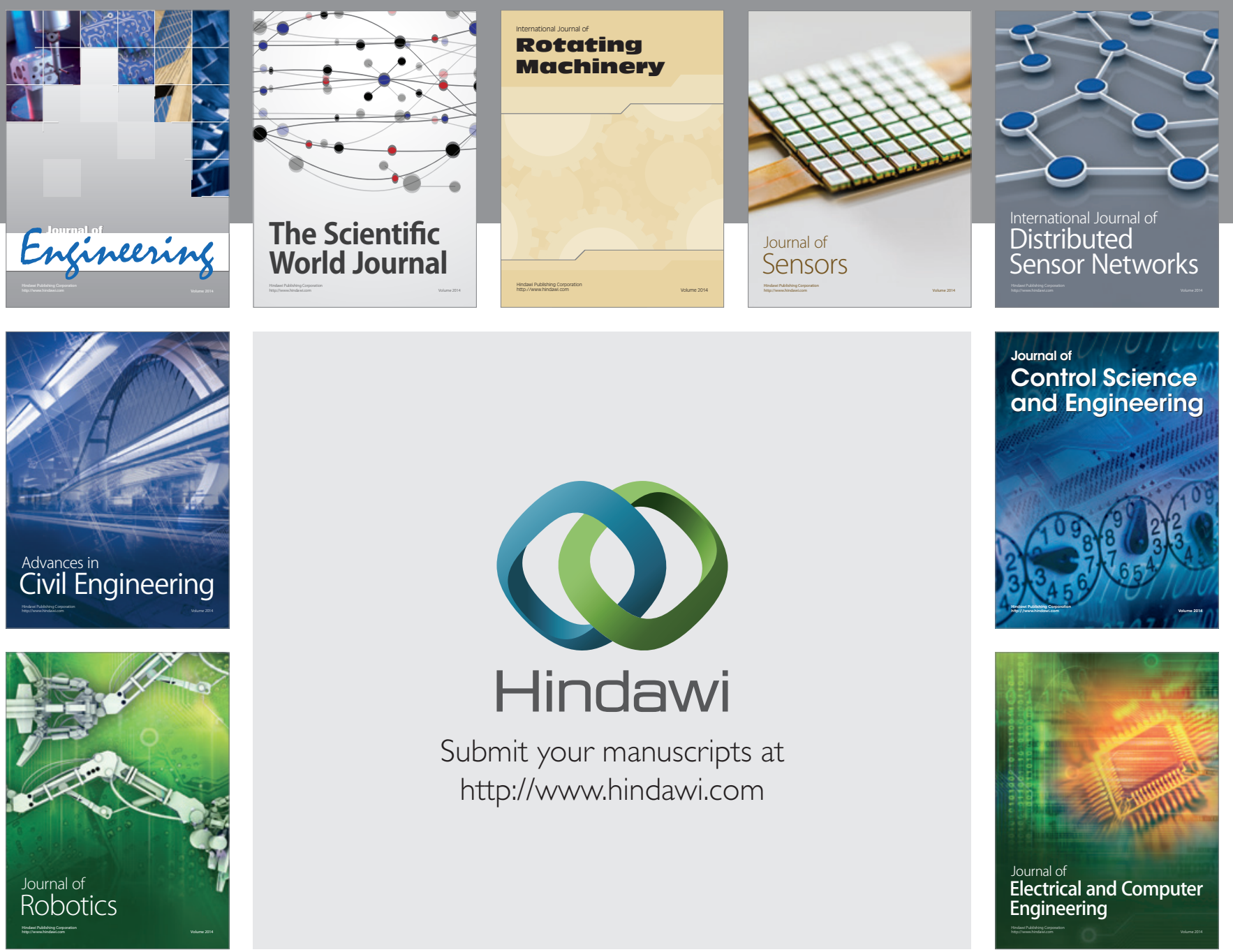

Submit your manuscripts at

http://www.hindawi.com
